\title{
A Qualitative Study of Individual and Organizational Learning through Physiotherapists' Participation in a Research Project
}

\author{
Petra Dannapfel*, Anneli Peolsson, Per Nilsen \\ Department of Medicine and Health, Linköping University, Linköping, Sweden \\ Email: ${ }^{*}$ petra.dannapfel@liu.se
}

Received 5 January 2014; revised 4 February 2014; accepted 3 March 2014

Copyright (C) 2014 by authors and Scientific Research Publishing Inc.

This work is licensed under the Creative Commons Attribution International License (CC BY). http://creativecommons.org/licenses/by/4.0/

\section{Open Access}

\section{Abstract}

The need for evidence-based practice has been recognized by physiotherapy organizations over the past decades. Earlier studies have documented facilitators and barriers that affect the use and implementation of evidence-based practice. Less is known about what kind of interventions might be useful to implement evidence-based practice. This study explores what physiotherapists learn through participation in a research project relevant to their professional development towards achieving a more evidence-based physiotherapy practice. To what extent this learning was transferred to colleagues for organizational learning is also examined. This study was set in Sweden, where health care is publicly funded. Patients do not need a referral from a physician to consult a physiotherapist. Eleven interviews were conducted with physiotherapists who had participated in a randomized, controlled, multicenter, physiotherapy intervention investigating neck-specific exercise for patients with whiplash disorder. Gadamer's hermeneutics was used to analyze the data. The physiotherapists described a range of learning experiences from their project participation, including instrumental learning (the concrete application of knowledge to achieve changes in practice) and conceptual learning (changes in knowledge, understanding or attitudes). The research project enabled the physiotherapists to develop new treatment techniques for broader application and extend their competence in techniques already known (instrumental learning). The physiotherapists believed that project participation enhanced their overall competence as physiotherapists, increased their job motivation and strengthened their self-confidence and self-efficacy (conceptual learning). Physiotherapists' participation in the research project yielded many individual learning experiences, fostered positive attitudes to research and was conducive to achieving a more research-informed physiotherapy practice. Participation was associated with a deeper understanding of the challenges involved in conducting research. The transfer from indi"Corresponding author. 
vidual learning to the wider organization in terms of organizational learning was limited.

Keywords

Evidence-Based Practice, Physiotherapy, Organizational Learning, Implementation

\section{Introduction}

The importance of attaining a more evidence-based practice to develop the physiotherapy profession has gained ground steadily over the past decade. However, research has identified numerous barriers to developing a more evidence-based physiotherapy practice, including physiotherapists’ perceived time restrictions, limited access to research, poor confidence in skills to identify and critically appraise research, and inadequate support from colleagues, managers and other health professionals [1]-[11]. Furthermore, limited research in some areas of physiotherapy constitutes an obstacle to practicing evidence-based physiotherapy [10].

However, studies that focus on implementation interventions to increase the use of evidence-based practice are scarce. The use of educational interventions to achieve increased evidence-based practice is one approach that has had a modest impact on the physiotherapists' clinical practice [5] [10]. Furthermore, two systematic reviews [12] [13] have concluded that active, multifaceted strategies for implementing guidelines were superior to passive strategies for improving knowledge and changing behaviour.

Another approach to implement and increase the use of evidence-based practice is collaboration between health professionals and researchers. Researchers such as [14]-[16] have highlighted the potential of collaboration between producers and users of research as a facilitator for research uptake in various practice contexts. However, more research is needed to evaluate how and to what extent this potential can be realized.

This study addresses an important knowledge gap concerning evidence-based physiotherapy practice. Based on interviews, the aim of this study was to explore what physiotherapists learn through participation in a research project relevant to their professional development and achieving a more evidence-based physiotherapy practice. The aim was also to explore how and to what extent this learning was transferred to colleagues for organizational learning. We have not been able to find any studies in the physiotherapy literature that have addressed this issue.

\section{Methods}

\subsection{Study Setting}

This study was set in Sweden. Health care in Sweden is publicly funded, that is, residents are insured by the state, with equal access for the entire population and fees regulated by law. The provision of health care services is the responsibility for the 21 county councils in Sweden [17].

There are approximately 21,000 registered physiotherapists in Sweden [17]. Patients can choose physiotherapists from the private or public sector (the charge is usually the same, albeit depending on whether the self-employed entrepreneurs are contracted to a county council or not) and they do not need a referral from a physician. Physiotherapists in Sweden are entitled to choose and perform any physiotherapeutic treatment technique they find suitable for the individual patient.

\subsection{Recruitment of Participants}

Participants for this study were recruited from treating physiotherapists in a prospective, randomized, controlled, multicenter, physiotherapy intervention study conducted by researchers in southern Sweden. The aim of the research project was to investigate whether neck-specific exercise with or without a behavioural intervention (performed by a physiotherapist) can improve functioning compared with a prescription of general physical activity for individuals with chronic (more than 6 months but less than 3 years) whiplash-associated disorders (WAD) with clinical findings verified from the neck, with and without additional neurologic symptoms in the arm. The whiplash study involved 216 patients and approximately 40 physiotherapists. The patients were randomized to one of three intervention arms: 1) prescription of general physical activity without neck-specific ex- 
ercises; 2) neck-specific exercises; and 3) neck-specific exercises in combination with an intervention based on knowledge from behavioural medicine.

The physiotherapists recruited from the whiplash study for interviews in our study treated patients in the neck-specific exercise group (intervention arm 2). Patients in this group performed neck-specific training (aiming to improve muscle coordination pattern and neck muscle endurance) supervised by a physiotherapist twice a week for 3 months at the physiotherapy clinic with additional exercises performed at home. The physiotherapists underwent half a day of education in theoretical and practical issues led by experienced physiotherapists from the research team. During the whiplash project, the physiotherapists could ask for support from the project leader at any time. They were not allowed to disseminate or perform any of the neck-specific training from the whiplash project in front of colleagues during the 3-month study period.

Twenty physiotherapists involved in the neck-specific exercise intervention arm in the whiplash study were approached for inclusion in our study via an e-mail that described the purpose and content of the study. The physiotherapists, both male and female, between 24 and 57 years of age, worked in various settings in different geographic locations. They had treated between 1 and 6 patients each in the intervention study. Intervention group 2 was chosen because the treatment was performed in the clinic and the physiotherapists experienced this method as novel compared with treatments they had previously used for neck-related problems.

A purposeful selection approach was used by sending the request to physiotherapists in the neck-specific exercise intervention arm who had performed neck-specific training with at least one patient and had worked at least 3 months after participating in the whiplash study (to allow for knowledge sharing with colleagues and patients not involved in the whiplash study). The study was approved by the regional ethical review board at Linköping University, Sweden.

\subsection{Data Collection}

Qualitative in-depth interviews with an open-ended structure were used to investigate what the physiotherapists learned from participation in the research project [18]. A semi-structured interview guide was developed by the three authors of the study. The interview guide was discussed and scrutinized in a seminar with researchers from different backgrounds, including physiotherapists, behavioural scientists, implementation researchers and organizational researchers. We used topics rather than specific questions to facilitate a broader approach to the study question.

The guide covered learning experiences from participating in the research project and the transfer of knowledge acquired and created from participation in the research project. Although there is no generally accepted definition of learning, there is considerable consensus among learning theorists that experiencing changes is inherent in the concept of learning [19]-[21]. The learning that takes place effects changes that can be expected to be more or less permanent, implying that the learner is now different from before the learning [22]. Building on a wide selection of theoretical approaches to learning, Illeris [23] proposes that learning is "any process that in living organisms leads to permanent capacity change and which is not solely due to biological maturation or ageing”.

Eleven physiotherapists agreed to participate in the study and were interviewed after giving informed consent. The selection of respondents varied with regard to clinical context, geographic location of the physiotherapists, their educational level and years of practice, age and sex (Table 1).

Table 1. Sociodemographic data of the focus group participants $(N=11)$.

\begin{tabular}{cc}
\hline Characteristic & Value \\
\hline Gender, $n$ (\%) female & $7(64)$ \\
Age, mean years (SD) & $44(13.0)$ \\
Range (years) & $26-65$ \\
Years of practice, mean years (SD) & $19(11.7)$ \\
Range (years) & $3-40$ \\
Number of patients $(N=7)$ & $4(1.9)$ \\
Range & $2-8$ \\
\hline
\end{tabular}


All interviews were conducted by the first author (PD) and lasted between 20 and 70 minutes. The interviews took place at the physiotherapists' workplace except one which took place at the physiotherapist's home. The respondents chose the place that was most suitable for them. The interviews were recorded with a dictaphone after permission was given by the interviewees. During the interviews, the respondents were sometimes asked for elucidation and further explanations to clarify their statements, in order to confirm the researchers' understanding of what was being said. Basic demographic data were collected on a form after the interview.

\subsection{Data Analysis}

All interviews were recorded and transcribed verbatim by the first author (PD). To validate the interpretation, analysis triangulation was performed [18]. This involved two researchers (PD and PN) interpreting the text independently of each other, followed by discussions until consensus was reached.

Gadamer's hermeneutics was used to achieve an understanding of the physiotherapists' learning from participation in research and how this learning was transferred to colleagues for organizational learning. Hermeneutics involves understanding of "the whole in terms of the detail and the detail in terms of the whole" in a circular relationship; when the parts harmonize, there is a reliable understanding [24]. Hermeneutics according to Gadamer concerns the understanding of an "otherness" through a systematic analytical process; it is a process to understand something in a new way. The researcher's preconceptions are not neglected, but rather these consistencies need to be accepted as a part of the analysis. One interpretation is dependent on the former interpretation, resulting in a new understanding created by the interpreter [24]. Understanding occurs when these horizons are fused with the researcher's perspective.

The hermeneutic analysis followed four guiding principles, as described by Gadamer [24]. Principle one involves reading transcribed interviews several times to obtain a sense of the whole. Principle two involves re-reading the text and asking open questions: that is, what is the understanding in the text; what does this stand for; what is the alternative interpretation; in what context is this being told. The analysis involved movement between the whole and its parts, participant by participant and dictum by dictum. Statements were found that created and elaborated meaning. Principle three requires the text to be interpreted from the horizon of the interpreter with the addition of literature and facts. This step included identification of clusters that provided a description and were representative of the overall text. Principle four involves fusion of the horizons from the participants and the interpreter. Once again, the verbatim transcription was reconsidered in relation to the horizons to validate and separate the horizons from each other. The focus was on finding expressions that contributed to an understanding of the physiotherapists' learning from participation in a research project. The interpretation of the data proceeded in a hermeneutic circle until consensus was reached.

\section{Results}

The interviews yielded rich texts that facilitated a detailed understanding of the physiotherapists' learning experiences from participation in the research project. The findings from the hermeneutic analysis are presented under two headings: physiotherapists' individual learning through participation in the research project and organizational learning by means of transferring physiotherapists' learning experiences to the broader organization.

\subsection{Individual Learning}

The project involved training the physiotherapists in the new treatment techniques, which they then used with the patients in the research study. Several physiotherapists believed that this pre-study training was important to develop the skills they then used as part of the research project. "I feel they [the research team] were very pedagogical in that we could train and go through the exercises and test them on each other. We had good instructions on how to do the exercises, which makes it easier to perform the exercises with the patients, when you know how they should feel and be performed."

The physiotherapists mentioned that several of the treatment techniques used in the research project was exercises that they had actually learned as part of their physiotherapy education, but had since forgotten about. Serving as a reminder, the research project enabled them to revive and use these techniques. Participation in the project thus contributed to improved understanding of how to apply knowledge they already had.

The physiotherapists experienced being involved in the research project as an opportunity to learn more and 
become more skilful in treating chronic whiplash-associated disorders, the specific problem being investigated in the study. Many physiotherapists mentioned that had been uncertain about how to treat patients with whiplash. Participation in the research project allowed them to gain confidence in dealing with this problem. "It's a lot of fun to get acquainted with this area, to learn more. I feel I now have deeper knowledge about something."

The physiotherapists believed their participation in the research project broadened their treatment technique and skills. "You broaden your repertoire and pick up things you wouldn't learn otherwise. I've gotten ideas and materials every time there has been a research study. It's something that remains with you; you can rely on what you've learned." "It has been rewarding for me as a physiotherapist; I've been able to develop my treatment techniques." They believed their learning benefited not only the patients involved in the intervention study but also other patients who did not take part in the study. "I have picked up some of the exercises and have used them with my other patients after the research project was over." "It's very relevant [to be able to use the training with other patients] and very rewarding and fun since we know they work. I feel I have been able to apply the new knowledge with my patients."

The physiotherapists also described learning in terms of obtaining a better understanding of neck problems generally and whiplash disorders more specifically. "I saw it as an opportunity to learn more about neck problems, to find a better way to treat these patients. It was great fun and I’ve learned a lot [by participating]. It's a way to keep updated."

Some physiotherapists also described that participation enabled them to question some of their current practices. "It [research project participation] creates a sort of awareness and curiosity concerning the topic. You become more reflective and there is less risk of working to a routine or working as you always have done." "It [research project participation] gives you new input, somehow, and it makes you think further.”

The physiotherapists mentioned that participation in a research project also increased their motivation for their job. "That's why it's so important to participate in this sort of thing. It somehow gives you a kick." "It becomes a trigger and makes you more motivated." "It makes it appealing to be part of the new, to get involved in everything new, because it gives you a small kick. It’s motivation.”

Some of the physiotherapists believed the research project yielded increased self-confidence and self-efficacy in their professional role. "You get more secure about how you should use the exercises when they have support in research, when you know that this treatment has an impact on neck pain." "I think we conveyed security and safety when we meet these patients because they know that they are meeting someone who has experience of this [the exercises] and knows what to do." "It creates a sense of security among the physiotherapists because they know how to perform these exercises." "We meet many neck patients and see them in training, but we don't always use methods [assessment and/or treatment techniques] based on the latest research or follow all the guidelines we have. I saw this project as an opportunity to get started and test what has proved to be effective in research."

The physiotherapists believed their participation in the research project contributed to making their practice more research informed. "I cannot prioritize [reading] articles to the same extent that I prioritize these patients who are involved in my study. Articles don't have the same impact [on clinical practice]. You put articles on the 'to-do' heap.” They described the project in terms of a very hands-on application of a more evidence-based practice. "I think you learn new treatment concepts by participating in the study and practicing it. If it works, you'll continue with the treatment. Learning by doing is the best way to learn. Some of the studies we read are very non-clinical." "Reading research and articles is very theoretical. You have to convert the theoretical knowledge into practice and action and that can be done in the training hall or in the treatment room. It's not always that you understand the theory [behind an assessment and/or treatment technique], so that's a barrier to transferring it to practice."

Research project participation triggered interest in and positive attitudes to research. "Now I must get involved and keep up with what's happening. It opens your eyes [to research].” Some physiotherapists remarked that many patients were pleased to be involved in the intervention study because they recognized that their treatment would be based on research findings, that is, more evidence-based. "The patients were very motivated to be part of the training programme. They were happy and safe when they left. They felt we had taken good care of them." Many of the physiotherapists expressed positive attitudes towards participation in further research studies. A few even considered becoming researchers themselves. "I'm intrigued to conduct research and to read [research]. I'm definitely interested in becoming a PhD student.”

Involvement in the research project fostered improved understanding of the research process. "It's clear that 
[participation in the research project] increases your understanding of how they arrive at various findings and conclusions." "Having been part of research provides a different understanding of research. When you read studies you recognize that they often miss details of what they did." At the same time, project participation yielded an increased appreciation for the challenges involved in doing research. "You realize how incredibly difficult it can be to undertake clinical studies. It's very difficult. There were lots of problems with the study so I never got to see what happened with all the patients." "It has been very, very tough because it's difficult to recruit these patients and do all the documentation. There was too much documentation that needed to be written and that was difficult. And all the considerations, what should I do if there is a two-week break. I realize that research studies need as much information as possible, but it's a balancing act of how many papers you can fill in.”

Some of the physiotherapists became more critical of findings from research as a result of their participation in the project. "I've actually become more sceptical of studies and findings in studies. I cannot criticize the study design because that has been excellent. However, my patient didn't follow the protocol. She should have trained for 3 months, but it was more than 4 months. And during this time she was here and trained in the gym five or six times, and that's what you should base research findings on. Many of my colleagues experienced this. It's difficult to achieve continuous uninterrupted training." "I can only speak about my patient and it's not possible to derive any research results on the basis of her training. Then you wonder about other studies. The study design may have been excellent, but what kind of results do you obtain?” The physiotherapists observed that the patients' engagement was crucial to achieve fidelity to the intervention, concluding that the patients play an important role in research to obtain valid and reliable results.

\subsection{Organizational Learning}

Many physiotherapists described that they discussed and shared learning experiences from their participation in the research project, both positive and negative, with colleagues who were not involved in the study. "I can imagine that they [colleagues] think we're whining quite a bit because of difficult patients we have talked about." "Physiotherapists are a funny breed; when something new comes around we are very curious, so colleagues have been interested in what I have been doing in the study. There's huge interest here.” Some physiotherapists mentioned that sharing knowledge is well integrated in their everyday work at their clinic, "I think that in this workplace, and in the county council in general, we are good at sharing knowledge with each other."

Although most physiotherapists described learning transfer in more informal terms, some of the physiotherapists mentioned that they had structured meetings with the expressed purpose of enabling knowledge sharing and achieving learning. "We've had meetings where we have discussed the research project. The interest has been tremendous." "We have quality improvement meetings and have had quality groups, and we work with development and improvement. Different groups are in charge of different areas and they examine research concerning how you should work and then we develop various care programmes. We meet twice a year to discuss and present things." "We have information meetings where we meet and discuss with colleagues. If we have the time, we share knowledge and experiences you pick up, like some training tips and some treatment tips. This is important because we [normally] work on our own with our patients."

However, although the physiotherapists typically had meetings devoted to knowledge and experience exchange, most of them complained that they had not been able to transfer learning from the research project at such meetings. "The results could have been exciting to bring up at a job meeting, but nothing like that has occurred." "Sad to say, but I don't discuss [the project] so much [with colleagues]. It's like you walk past each other; you don't stop to reflect." "We have not had any internal education based on this particular study, but I think physiotherapists in this workplace and in the county council in general are very good at sharing knowledge. We usually have an education day where you talk about what you have experienced and various advice, etc.”

Some of the physiotherapists believed their participation in the research project contributed to creating a more research-informed culture in their clinic by means of their discussions and reflection with colleagues. "It [research] becomes more real, somehow, when people you know have participated. It makes it [research] more concrete. It's more mysterious and abstract when research is done at universities." "It's very important for the patients to recognize that we are doing research at this clinic, that they know that it is positive. It's important that they [patients] see that we're a unit that works scientifically."

However, the physiotherapists also brought up time pressures that restrict opportunities to transfer knowledge to colleagues and the wider organization. "We are usually fully booked and have a lot to do. But you want to 
learn things that can be useful in your work." "It can inhibit dissemination of research if you take part in too many studies." Some of the physiotherapists mentioned that the focus on production has increased, inhibiting learning and reflection opportunities. "We previously had a better network for sharing knowledge in the region, but now several of the managers don't prioritize this. Instead, they want their physiotherapists to be at the clinic." "Network meetings take time, but in my opinion such meetings were valuable because you discuss with colleagues from other clinics, you spread knowledge and learn from a wider group. This was better 15 - 20 years ago.”

\section{Discussion}

This study explores physiotherapists' learning through participation in a research project. The physiotherapists described a broad range of learning experiences resulting from their project participation. The project yielded both instrumental and conceptual learning; the former concept is the concrete application of knowledge to achieve changes in practice and the latter concept denotes changes in knowledge, understanding or attitudes [25]. The research project enabled the physiotherapists to develop new treatment technique skills for broader application and extend their competence in techniques that they already knew about (i.e. instrumental learning). The physiotherapists believed that project participation enhanced their overall competence as physiotherapists, increased their motivation for their job and strengthened their self-confidence and self-efficacy in their professional role (i.e. conceptual learning).

Most of the learning experiences described by the physiotherapists can be characterized as single-loop learning; that is, the learning primarily involved improved problem solving within a given set of norms and procedures [26]. However, there were also some instances of double-loop learning, which involves surfacing and challenging assumptions that have previously been taken for granted [19] [26] [27]. For example, some physiotherapists described how participation in the research project led them to question some of their current work practices and made them more critical of research findings. Double-loop learning is broadly similar to Engeström's [28] “expansive learning”, Mezirow’s [29] “transformative learning” and Ellström’s [30] “creative learning", that is, concepts that refer to a type of learning that occurs when individuals or groups in an organization break out from established thought and action patterns to develop new ways of handling problems involving their work.

Involvement in the research project influenced the physiotherapists' interest and attitudes to research in general. Attitudes towards research have been identified as a key factor in research use among physiotherapists; more positive attitudes are associated with a higher degree of use of research findings in routine practice [3] [6] [8] [31] [32]. The physiotherapists in our study seemed to gain a deeper understanding of the research process as they recognized some of the challenges involved in conducting research. This finding is consistent with Austin's [33] analytical study on learning in organizations, in which it was suggested that collaboration between researchers and health care practitioners can improve the practitioners' abilities to critically appraise research and increase their use of research in clinical practice. It is important to be able to critically appraise research and be able to evaluate if the intervention is suitable for implementation or use in the clinic or for a specific patient. Thus, research should not be implemented as default. However, the physiotherapists in our study voiced critical opinions about the validity and reliability of research findings as they struggled with patients who did not adhere to the intervention.

The physiotherapists believed that their involvement in the research project facilitated increased use of research findings in their practice. Hence, our findings clearly suggest that interaction between researchers and practitioners could be a means of achieving a more evidence-based practice, as has been suggested by some researchers [14]-[16]. Kitson et al. [16] have argued that researchers in collaboration with stakeholders could benefit from being partners in problem solving and knowledge co-creation. Collaboration in all steps of the production of research and co-creation of new knowledge might facilitate deeper understanding from both researchers and practitioners regarding the whole process from conducting research to implementing the research results in clinical practice.

The study also explores how and to what extent the physiotherapists' individual learning from participating in the project was transferred to others in the organization and how it benefited organizational learning. Organizations learn through its individual members, yet organizational learning is not simply the sum of the learning of each of its members. Organizations are assumed to learn in a way analogous to individual learning and theories 
of individual learning are often extended to the group or organizational level [27]. Hence, organizational learning can be conceived as a process that results in relatively lasting changes in organizational practices due to changes in routines, rules, norms, strategies and technologies that are assumed to guide the behaviour of the organization's members [34] [35]. The question, then, is to what extent did the physiotherapists' research project participation lead to change in actions in their workplaces? Our findings provide little evidence of such changes taking place, suggesting that organizational learning was limited.

The physiotherapists described few formal opportunities for sharing their learning from the research project with others in their workplace. A lack of structured meetings for knowledge capturing and sharing has also been noted by Bourne et al. [36] in a survey study investigating professional, educational and personal needs among physiotherapists in community settings. Bourne et al. [36] found that most physiotherapists had no formal opportunity to discuss research findings with colleagues which affected their ability to meet the demands of an evidence-based practice. Some of the physiotherapists in our study did have more structured meetings at their workplace where knowledge sharing was on the agenda although the physiotherapists' had not been requested to share experiences from the research project at such meetings. The tension between production and time for activities that involve learning, knowledge sharing and reflection is well known in many fields of work and not unique to physiotherapy. An obvious difficulty in establishing a balance between production and learning is that the benefits of learning activities are more remote in time and less reliable than the easily calculated value of activities that boost day-to-day production [37]. Changes in health care systems, including Sweden's, have led to higher demands on physiotherapists to provide effective and efficient management of patients amidst high patient turnover.

The transfer of the physiotherapists' individual learning from participation in the research project to the wider organization largely relied on informal channels in the form of everyday social encounters with colleagues. Knowledge that the physiotherapists acquired in the research project mostly remained personal, subjective and context specific. Many researchers have emphasized the importance of creating formal structures and procedures to facilitate and support workplace learning, knowledge sharing and reflection because these activities are usually not given priority in many organizations [37].

Our study points to the importance of informal learning that is, learning that occurs continuously in everyday experience in contrast to formal learning which takes place outside the working environment, typically in classroom-based formal educational settings [38]. Importance of informal learning for acquiring and developing the competencies required at work has been increasingly recognized. Marsick and Watkins [39] have argued that four-fifths of what employees learn comes from informal workplace learning, whereas formalized, structured training only represents $20 \%$. Other estimates claim that closer to $90 \%$ of learning takes place through informal means [40]. Although informal learning is usually described in positive terms, some researchers have also highlighted drawbacks associated with this type of learning. For instance, Dale and Bell [41] point out that practitioners may learn bad habits or the wrong lessons if they rely too much on informal learning, whereas Conlon [42] suggests that informal learning can leave practitioners feeling directionless.

Our findings on the challenges of transferring individual learning to the wider organization are consistent with studies in project-based organizations, which have generally concluded that organizations fail to learn from projects. Even where significant individual learning is generated within projects, there are often substantial difficulties in capturing or translating this learning into new practices at the level of the organization [19] [43]-[45]. As each new project is started, there is a tendency to reinvent the wheel rather than learn from the experiences of previous projects [46]. Such observations are in line with our findings that the physiotherapists' knowledge obtained from the research project remained an individual learning experience because their knowledge was shared with few people.

This study has some shortcomings that must be considered when interpreting the findings. The study was conducted in Sweden, and the transferability of the findings beyond the context of the Swedish health care system might be limited. All organizations have their own culture and mental models of how learning routines and learning processes should be prioritized and performed, which may also affect the transferability of the results. Furthermore, the interviews may not have been fully representative of all types of physiotherapists in Sweden.

\section{Conclusions}

In conclusion, the physiotherapists' participation in the research project yielded many individual learning ex- 
periences. Participation fostered positive attitudes to research and was conducive to achieving a research-informed physiotherapy practice. Participation was associated with a deeper understanding of the challenges involved in conducting research. However, our study also demonstrated that organizational learning concerning the research project was limited because transfer of individual learning to the wider organization was limited. There was a paucity of formal learning opportunities at which knowledge could be shared, meaning that learning was largely informal.

In terms of clinical implications, this study proposes that collaboration between practitioners and researchers in implementing research results in clinical practice could be beneficial for both practitioners and researchers. The study also highlights the need for more formal forums where practitioners can share learning experiences gained in research project participation to allow for organizational learning. These forums should be supported by facilitating organizational structures and processes for the uptake of individual learning at group and organizational learning levels.

\section{References}

[1] Barnard, S. and Wiles, R. (2001) Evidence-Based Physiotherapy: Physiotherapists' Attitudes and Experiences in the Wessex Area. Physiotherapy, 87, 115-124. http://dx.doi.org/10.1016/S0031-9406(05)61078-4

[2] Kamwendo, K. (2002) What Do Swedish Physiotherapists Feel About Research? A Survey of Perceptions, Attitudes, Intentions and Engagement. Physiotherapy Research International, 7, 23-34. http://dx.doi.org/10.1002/pri.238

[3] Jette, D.U., Bacon, K., Batty, C., Carlson, M., Ferland, A., Hemingway, R.D., Hill, J.C., Ogilvie, L. and Volk, D. (2003) Evidence-Based Practice: Beliefs, Attitudes, Knowledge, and Behavior of Physical Therapists. Physical Therapy, 83, 786-805.

[4] Palfreyman, S., Tod, A. and Doyle, J. (2003) Comparing Evidence-Based Practice of Nurses and Physiotherapists. British Journal of Nursing, 12, 246-253.

[5] Stevenson, K., Phil, M., Lewis, M. and Hay, E. (2004) Do Physiotherapists’ Attitudes towards Evidence-Based Practice Change as a Result of an Evidence-Based Educational Program. Journal of Evaluation in Clinical Practice, 10, 207-217. http://dx.doi.org/10.1111/j.1365-2753.2003.00479.x

[6] Iles, R. and Davidson, M. (2006) Evidence Based Practice: A Survey of Physiotherapists' Current Practice. Physiotherapy Research International, 11, 93-103. http://dx.doi.org/10.1002/pri.328

[7] Grimmer-Somers, K., Lekkas, P., Nyland, L., Young, A. and Kumar, S. (2007) Perspectives on Research Evidence and Clinical Practice: A Survey of Australian Physiotherapists. Physiotherapy Research International, 12, 147-161. http://dx.doi.org/10.1002/pri.363

[8] Hannes, K., Staes, F., Goedhuys J. and Aertgeerts, B. (2009) Obstacles to the Implementation of Evidence-Based Physiotherapy in Practice: A Focus Group-Based Study in Belgium (Flanders). Physiotherapy Theory and Practice, 25, 476-488. http://dx.doi.org/10.3109/09593980802661949

[9] Nilsagård, Y. and Lohse, G. (2010) Evidence-Based Physiotherapy: A Survey of Knowledge, Behaviour, Attitudes and Prerequisites. Advances in Physiotherapy, 12, 179-186. http://dx.doi.org/10.3109/14038196.2010.503812

[10] Fruth, S.J., van Veld, R.D., Despos, C.A., Martin, R.D., Hecker, A. and Sincroft, E.E. (2010) The Influence of a TopicSpecific Research-Based Presentation on Therapists' Beliefs and Practices Regarding Evidence-Based Practice. Physiotherapy Theory and Practice, 26, 537-557. http://dx.doi.org/10.3109/09593980903585034

[11] Bernhardsson, S. and Larsson, M.E. (2013) Measuring Evidence-Based Practice in Physical Therapy: Translation, Adaption, Further Development, Validation, and Reliability Test of a Questionnaire. Physical Therapy, 93, 819-832. http://dx.doi.org/10.2522/ptj.20120270

[12] Van der Wees, P.J., Jamtvedt, G., Rebbeck, T., de Bie, R.A., Dekker, J. and Hendriks. E.J.M. (2008) Multifaceted Strategies May Increase Implementation of Physiotherapy Clinical Guidelines: A Systematic Review. Australian Journal of Physiotherapy, 54, 233-241. http://dx.doi.org/10.1016/S0004-9514(08)70002-3

[13] Menon, A., Korner-Bitensky, N., Kastner, M., McKibbon, K.A. and Straus, S. (2009) Strategies for Rehabilitation Professionals to Move Evidence-Based Knowledge into Practice: A Systematic Review. Journal of Rehabilitation Medicine, 41, 1024-1032. http://dx.doi.org/10.2340/16501977-0451

[14] Fixsen, D.L., Naoom, S.F., Blase, K.A., Friedman, R.M. and Wallace, F. (2005) Implementation Research: A Synthesis of the Literature. University of South Florida, Louis de la Parte Florida Mental Health Institute, The National Implementation Research Network, Tampa, FMHI Publication \#231.

[15] Nutley, S.M., Walter, I. and Davies, H.T.O. (2007) Using Evidence: How Research Can Inform Public Services. The Policy Press, Bristol. 
[16] Kitson, A., Powell, K., Hoon, E., Newbury, J., Wilson, A. and Beilby, J. (2013) Knowledge Translation within a Population Health Study: How Do You Do It. Implementation Science, 8, 54. http://dx.doi.org/10.1186/1748-5908-8-54

[17] Sveriges Officiella Statistik, Statistik om hälso-och sjukvårdspersonal. Officiell statistik om antal legitimerade (2010) och arbetsmarknadsstatus (2009) (Statistics for Health Care Professionals. Official Statistics on the Number Licensed (2010) and Social Status (2009)) National Board of Health and Welfare, Stockholm, 2010. http://www.socialstyrelsen.se/Lists/Artikelkatalog/Attachments/18486/2011-11-13.pdf

[18] Patton, M.Q. (2002) Qualitative Research and Evaluation Methods. Sage Publications, Thousand Oaks.

[19] Argyris, C. and Schon, D. (1974) Theory in Practice. Jossey-Bass, San Francisco.

[20] Marton, F. and Booth, S. (2000) Om lärande. Studentlitteratur, Lund.

[21] Ellström, P.E. (1992) Kompetens, utbildning och lärande i arbetslivet. Publica, Stockholm.

[22] Crow, A. (1972) Educational Psychology. Littlefield, Adams, Totowa.

[23] Illeris, K. (2007) Lärande. Studentlitteratur, Lund, p. 3.

[24] Gadamer, H.G. (2004) Truth and Method. Continuum International Publishing Group, London.

[25] Estabrooks, C.A. (1999) The Conceptual Structure of Research Utilization. Research in Nursing \& Health, 22, 203216. http://dx.doi.org/10.1002/(SICI)1098-240X(199906)22:3<203::AID-NUR3>3.0.CO;2-9

[26] Argyris, C. (2006) Integrating the Individual and the Organization. Transaction Publishers, London.

[27] Kim, D.H. (1993) The Link between Individual and Organizational Learning. Sloan Management Review (Fall), 3750 .

[28] Engeström, Y. (1988) Learning by Expanding. University of Helsinki, Helsinki.

[29] Mezirow, J. (1991) Transformative Dimensions of Adult Learning. Jossey-Bass, San Francisco.

[30] Ellström, P.E. (2001) Integrating Learning and Work: Problems and Prospects. Human Resource Development Quarterly, 12, 421-435. http://dx.doi.org/10.1002/hrdq.1006

[31] Dannapfel, P., Peolsson, A. and Nilsen, P. (2013) What Supports Physiotherapists' Use of Research in Clinical Practice? A Qualitative Study in Sweden. Implementation Science, 8, 31. http://dx.doi.org/10.1186/1748-5908-8-31

[32] Salbach, N.M., Guilcher, S.J.T., Jaglal, S.B. and Davies, D.A. (2010) Determinants of Research Use in Clinical Decision Making Among Physical Therapists Providing Service Post-Stroke: A Cross-Sectional Study. Implementation Science, 5, 77. http://dx.doi.org/10.1186/1748-5908-5-77

[33] Austin, M.J. (2008) Strategies for Transforming Human Service Organizations into Learning Organizations: Knowledge Management and the Transfer of Learning. Journal of Evidence-Based Social Work, 5, 569-596. http://dx.doi.org/10.1080/15433710802084326

[34] Swan, J., Scarbrough, H. and Newell, S. (2010) Why Don’t (or Do) Organizations Learn from Projects? Management Learning, 41, 325-344. http://dx.doi.org/10.1177/1350507609357003

[35] Easterby-Smith, M. and Lyles, M.A. (2011) The Evolving Field of Organizational Learning and Knowledge Management. In: Easterby-Smith, M. and Lyles, M.A., Eds., Handbook of Organizational Learning \& Knowledge Management, 2nd Edition, John Wiley, Chichester, 1-22.

[36] Bourne, J.A., Dziedzic, K., Morris, S.J., Jones P.W. and Sim, J. (2007) Survey of the Perceived Professional, Educational and Personal Needs of Physiotherapists in Primary Care and Community Settings. Health \& Social Care in the Community, 15, 231-237. http://dx.doi.org/10.1111/j.1365-2524.2007.00677.x

[37] Nilsen, P., Nordström, G. and Ellström, P.E. (2011) Integrating Research-Based and Practice-Based Knowledge through Workplace Reflection. Journal of Workplace Learning, 24, 403-415. http://dx.doi.org/10.1108/13665621211250306

[38] Malcolm, J., Hodkonson, P. and Colley, H. (2003) The Interrelationships between Informal and Formal Learning. Journal of Workplace Learning, 15, 313-318. http://dx.doi.org/10.1108/13665620310504783

[39] Marsick, V. and Watkins, K. (1990) Informal and Incidental Learning in the Workplace. Routledge, New York.

[40] Sohoran, E. (1993) We Do; Therefore We Learn. Training and Development, 4, 47-52.

[41] Dale, M. and Bell, J. (1999) Informal Learning in the Workplace. Research Brief No. 134, Department for Education and Employment, London.

[42] Conlon, T.J. (2004) A Review of Informal Learning Literature, Theory, and Implications for Practice in Developing Global Professional Competence. Journal of European Industrial Training, 28, 283-295. http://dx.doi.org/10.1108/03090590410527663

[43] Prencipe, A. and Tell, F. (2001) Inter-Project Learning: Processes and Outcomes of Knowledge Codification in Pro- 
P. Dannapfel et al.

ject-Based Firms. Research Policy, 30, 1373-1394. http://dx.doi.org/10.1016/S0048-7333(01)00157-3

[44] Newell, S., Bresnen, M., Edelman, L., Scarbrough, H. and Swan, J. (2006) Sharing Knowledge across Projects: Limits to ICT-Led Project Review Practices. Management Learning, 37, 167-185. http://dx.doi.org/10.1177/1350507606063441

[45] Eraut, M. (2004) Informal Learning in the Workplace. Studies in Continuing Education, 26, 247-273. http://dx.doi.org/10.1080/158037042000225245

[46] Prusak, L. (1997) Knowledge in Organizations. Butterworth-Heinemann, Newton. 